\title{
Simulator to Improve the Productivity of Yogurt Processing Based on a Model of Finite Automaton
}

\author{
C. Ramírez-Martín ${ }^{\# 1}$, Nairo Cavieles-Rojas ${ }^{* 2}$, Nelson Méndez-Salamanca ${ }^{+3}$, \\ Ricardo Cifuentes-Osorio ${ }^{\&}$, Mauricio Ochoa-Echeverria ${ }^{\text {}}$ \\ \# Physics Department, Universidad de Boyacá, 150003 Tunja, Colombia \\ ${ }^{1}$ Corresponding Author's: cramirezm@uniboyaca.edu.co \\ * Mechatronics Engineering, Universidad de Boyacá, 150003 Tunja, Colombia \\ 2 njcavieles@uniboyaca.edu.co \\ Systems Engineer, Research Group CISNHE and SISTECBIO, Universidad Manuela Beltran \\ 680003 Bucaramanga, Colombia \\ 3 nelson_mendezumb@hotmail.com \\ ${ }^{\&}$ Faculty of Science and Engineering, Universidad de Boyacá, 150003 Tunja, Colombia \\ ${ }^{4}$ grcifuentes@uniboyaca.edu.co \\ ¥ Systems Engineer, Universidad de Boyacá, 150003 Tunja, Colombia \\ ${ }^{5}$ m.ochoa@uniboyaca.edu.co
}

\begin{abstract}
The technological tools contribute to the leverage of PymES (small and medium enterprises) in their productive processes. The developed simulator presents a friendly interface that facilitates the manipulation and interpretation of the information of the mathematical model of the process of industrial manufacturing of yogurt; through the implementation of the user's communication with a database system that allows to classify and store the information related to this process, guaranteeing compliance with the requirements of the system through the execution of tests. The simulator complies with the stages of the RUP methodology and has two levels of security, allowing the end user to carry out follow-ups that help determine faults in the production process to obtain high-quality products.
\end{abstract}

Keyword - Automaton, model, state diagram, simulator

\section{INTRODUCTION}

The process of production of yogurt can be automated as well as the processing of other foods, which allows to optimize it to increase the productivity and the quality of the products. This can be achieved by creating mathematical models to design simulators, which in turn allow decisions to be made in a timely manner before or during the process, and which in turn show the process sequentially and realistically. The finite automata have been used in different automation processes due to their characteristic mathematical model composed of discrete inputs and outputs that occur in different states. The state of the system can determine the behavior of the system based on the previous entries and the following entries [1-2].

Finite automata represent one of the fundamental elementary models of computer algorithms. There is an elaborate theory about problems that can be solved both with and concerning the finite automata that is now taught in the basic theoretical courses. When dealing with algorithmic questions about finite automata such as the problem of words, the problems of emptiness and finitude, the problem of equivalence or the minimization of such automatons, such questions are treated by analyzing the Turing computation model as an underlying computational model [3]

The non-deterministic finite automata (NFA) were introduced in [4], where their equivalence with finite deterministic automata (DFA) was shown. Later, the concept of alternation was developed in [5], where alternating finite automata (AFA) were also investigated, which also turned out to be equivalent to DFA. It is well known that NFAs can offer exponential savings in the number of states compared to deterministic finite automata (DFA). A similar result also applies to AFA simulated by DFA with an adjusted double exponential state limit of 22n shown in [5]. Much work has been done in the study of the descriptive complexity of the simulation of and by various types of automata and in the computational complexity of decision problems related to finite automata [6].

In recent years, theoretical computer science has seen a growing interest in the alternative to Turing computer models. The reader could think of quantum computers [7], neural networks [8], analog computers [9], various types of biologically inspired devices [10] and models for computations on real and complex numbers. Models for the latter are divided into approaches based on the Turing machine, such as those followed in recursive analysis [11] and in algebraically inspired notions of algorithms [12,13]. One characteristic of such algorithm models is that they no longer work exclusively on finite alphabets as underlying structures. 


\section{MATERIALS AND METHODS}

The solution to the problem presented was focused on a simulator developed based on a finite automaton and for which the following stages were established

\section{A. Selection of Variables}

According to the standard [14], the physicochemical and microbiological parameters that influence the obtaining of the product were selected. Tests of specific gravity, fat, total dry extract, acidity, cryoscopic index and refractive index were made to the raw material. Also, during the process of making the yogurt the time and temperature of the finished product was monitored, the content of fat, lactic solids, acidity, total coliforms and E. coli was verified

\section{B. Preparation of Yogurth}

After analyzing various sources on yogurt processing, a variety of flow diagrams were found to be involved in the elaboration process, in such a way that a block diagram representative of the processing of yoghurt was compiled, as shown in the Fig. 1.

Once the main stages of the yoghurt process were identified, the different sub-stages were established, which were documented through different sources where a greater preference was observed towards the processing of fruity yoghurt, which is why in the design of the finite automaton it was decided to develop a more robust model and that therefore allowed to simulate any kind of yogurt [15].

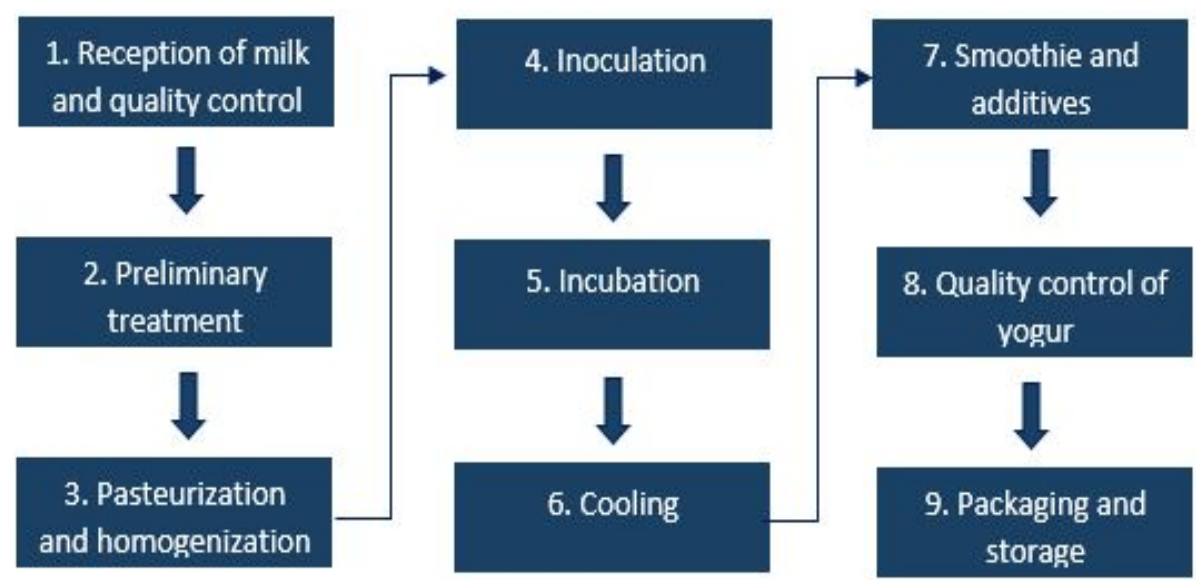

Fig. 1. Block diagram of the yogurt process [16]

\section{Elaboration of the Mathematical Model}

The variables that intervene in each stage of the process were evaluated together with the instruments and mechanisms used to measure them, based on the above, a flow diagram of the process was elaborated and physicochemical relations or laws among these variables were examined, which determined the behavior of the process and that served to formulate a deterministic mathematical model, consisting of a group of matrices.

The matrices constructed for the elaboration of the yogurt are: the matrix of the process, the table of states and the matrix by stages. Once the matrices were created, we proceeded to elaborate the graphical model, which consists of a sequential diagram of states, with routes that lead to another state or to make a decision, depending on the value of the variables in that state.

\section{Development of the Simulator}

For the development of the simulator, the four phases considered in the RUP methodology were used. In the start or inception phase, the aim is to establish the scope and limits of the project, acceptance criteria and the characteristics of the system, identification of the use cases and main scenarios of the system, estimating costs and project tasks, estimating the risks potential of the project to achieve an understanding of the development environment of the system that will be executed.

In the iteration phase, we seek to comply with the development of the necessary artifacts and milestones in this phase in a correct and optimal way to avoid changes to the system through iterations and identification of risks, verifying the accomplishment of the tasks.

The test plan seeks to provide information about the objectives of the tests that can be carried out in the project, identify the strategies, their objectives, the level of coverage and the resources necessary to implement and execute it. The established tests are: Unit code tests, System tests, Integration test, Beta test, Recovery test, Safety test, Resistance test, Regression test and Acceptance test. 
In the configuration management plan, the objective is to provide the infrastructure and the environment of product development while ensuring that the configuration of the environment facilitates the revision, changes and defects of the product through a follow-up. It controls the numerous artifacts that are produced in the development to avoid that they are not carried out simultaneously, that the changes made in them are notified and that they are implemented immediately [17].

\section{RESULTS}

Matrices were developed as: Matrix of the process, the Table of states and the Matrix by stages, characterized by the optimal intervals of each variable in the process, the theoretical foundations for each variable, the determination of the measuring instrument and laboratory elements.

The complete process is represented by sub-steps in a sequential manner, where the permitted intervals for each variable can be observed according to the regulations in force, together with the causes and effects of exceeding the permitted ranges.

\section{A. Automaton Model}

A graphic model of the automaton was developed, made on the Microsoft Visio ${ }^{\circledR}$ application which defines the processing of yogurt. In the Fig. 2, the diagram of states of the automaton is schematized, constituting the base for the development of the simulator.

\section{B. Simulator}

For the development of the simulator, the methodology of object-oriented analysis and design (OO) was taken into account, allowing the data to be considered as separate elements of the processes that transform it; at the same time, it facilitates the evolution outside the process and the creation of consistent models. The RUP methodology, "Rational Unified Process" was used under the Visual Basic programming language. NET®.

\section{DIAGRAM OF STATES OR AUTOMATA DEFINING YOGUR PROCESSING}

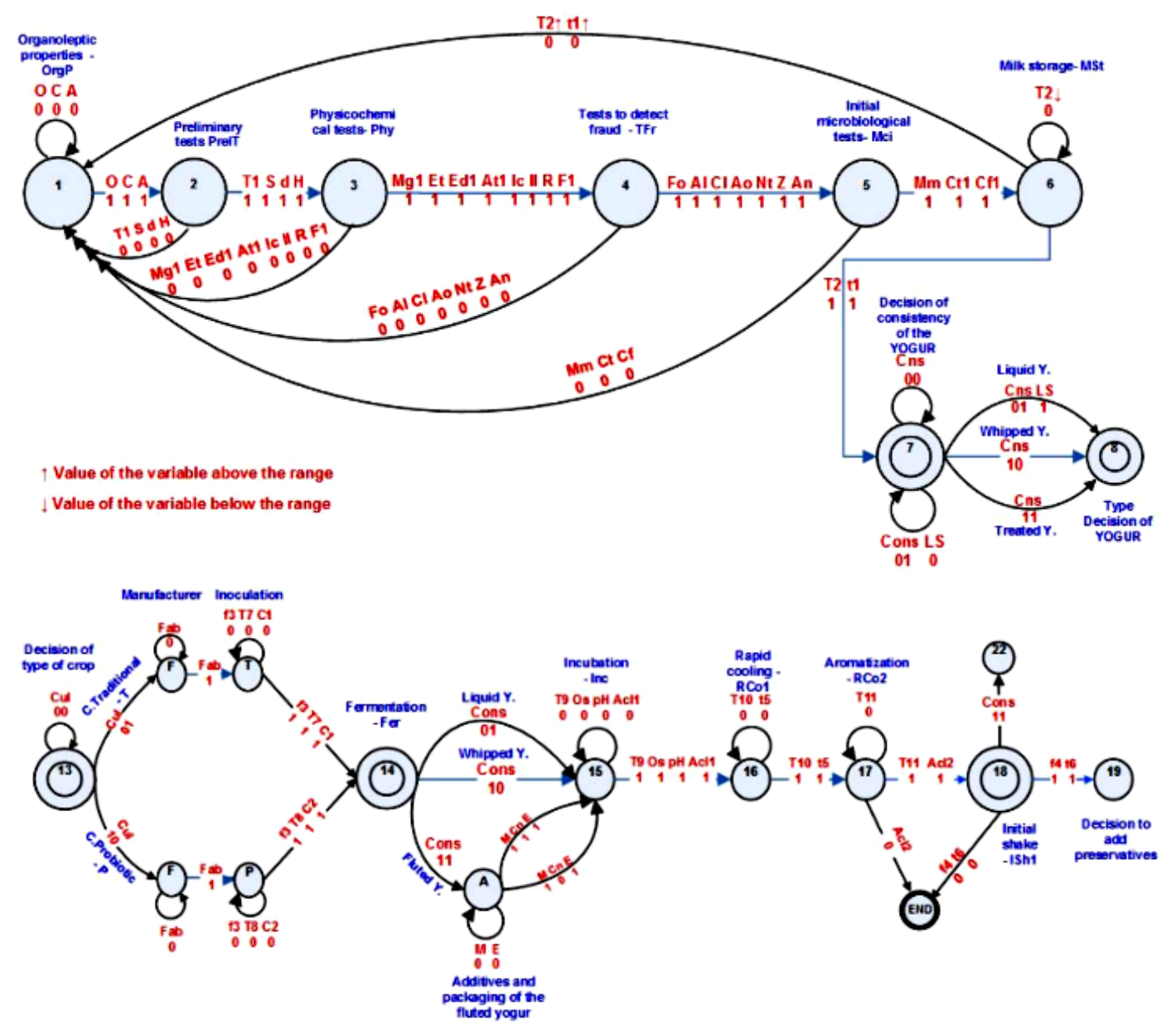



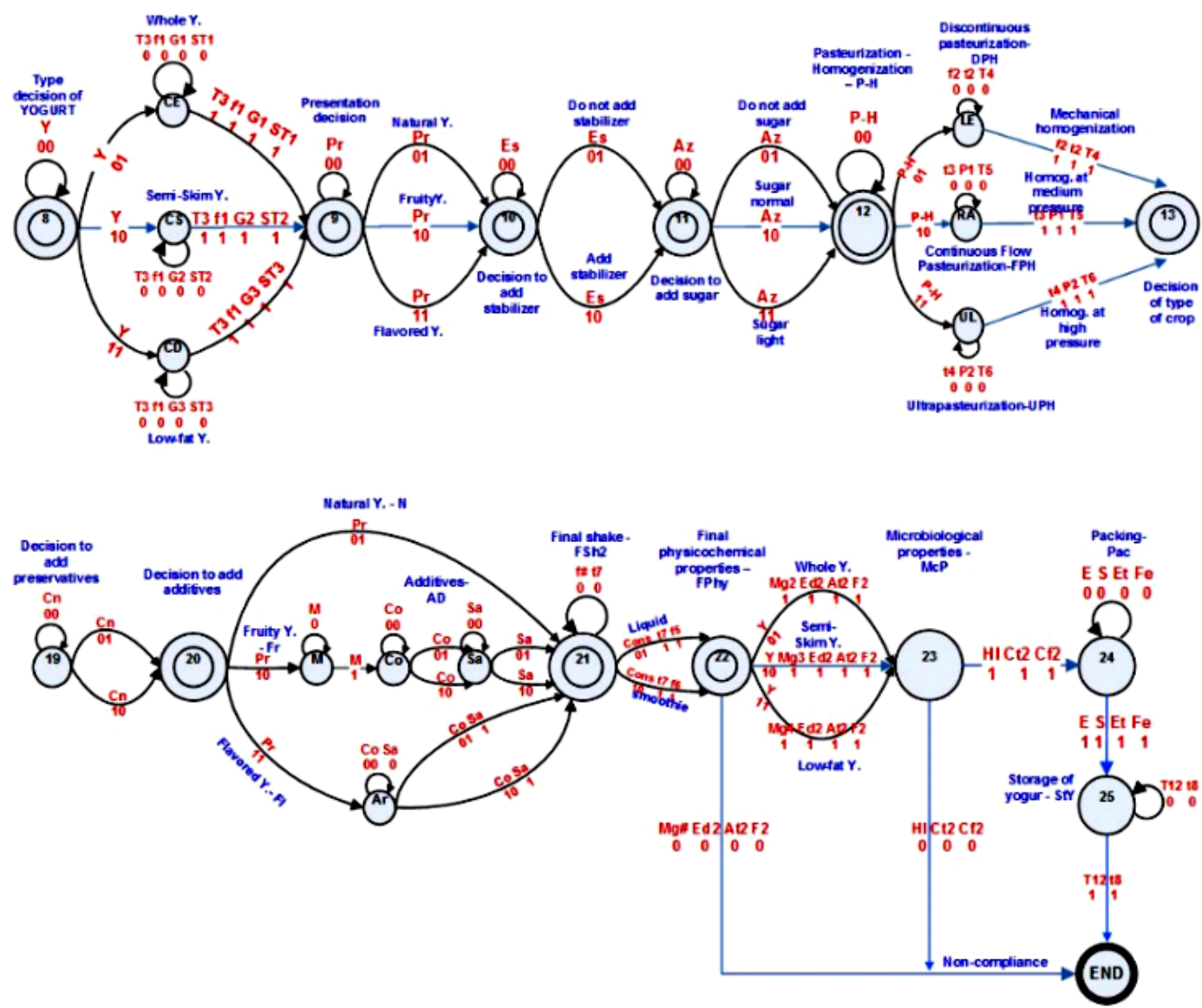

Fig. 2. Statistical diagram of the automaton that defines the processing of yogurt [18]

The development was based on the four stages of this methodology: Inception, Elaboration, Construction and Transition, since it achieves the monitoring and development of quality software, provides each user with easy access to the knowledge base with guides, templates and tools for all critical development activities, while creating and maintaining models, instead of focusing on the production of a large number of documentation papers.

The tool has been conceived as a real simulation of the issues involved in the planning and execution of the industrial processing of yogurt with a high degree of precision, which allows a deep and true analysis of all the variables involved in its preparation and the relationships that exist between them, so that the level of decisions taken from this tool are concrete and real, allowing to improve market competitiveness, experiment, learn to decide according to the situation, apply knowledge, training in the process, observe the behavior of the variables, correct deficiencies and solve problems through a simple and user-friendly interface.

The results of the analysis of the simulator can predict profitability, determine the level of production performance, production costs, optimization of the time-performance relationship of the process, while allowing the management of statistics. The simulator developed for the industrial processing of yogurt, has two levels of security for the exclusive use of the administrator (level one) or their respective users (level two).

Level One users can perform operations throughout the menu, without any restrictions. You can move through the main menus like: Administrator/ Simulator/Queries/ Reports/ Statistics/ Simulation. Level Two users can only access and make changes to the following main menus. Simulator/Queries/Reports/Statistics/Simulation.

The main screen will be in charge of establishing the communication between the user and the different processes that are carried out, this through the menus. This screen will be present during the time the simulator is open for the industrial production of yogurt. In the Main screen you will find the different accesses (Menus) to the other screens.

The user of the Software in this case, exclusively the administrator, can enter the data required for a new type of yogurt as shown by the submenus of each of the main menus of the project. By clicking on the Administrator menu, this displays a list with the different information that you need to have for the preparation of the final product. In Fig. 3, the administrator form allows the entry corresponding to the information of the type of user that may exist for program management. 


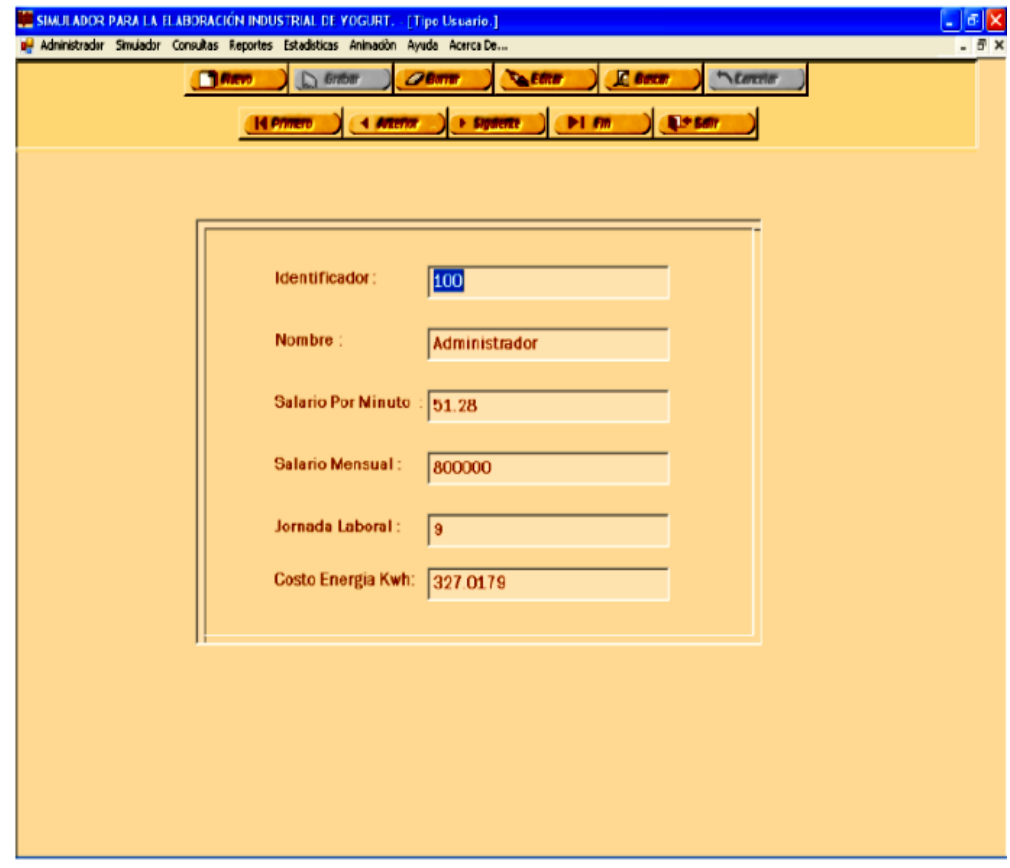

Fig. 3. Administrador Form/User Type [17]

In Fig. 4, the physicochemical tests form allows the entry of the corresponding data to said test at the moment of the collection and its respective cost.

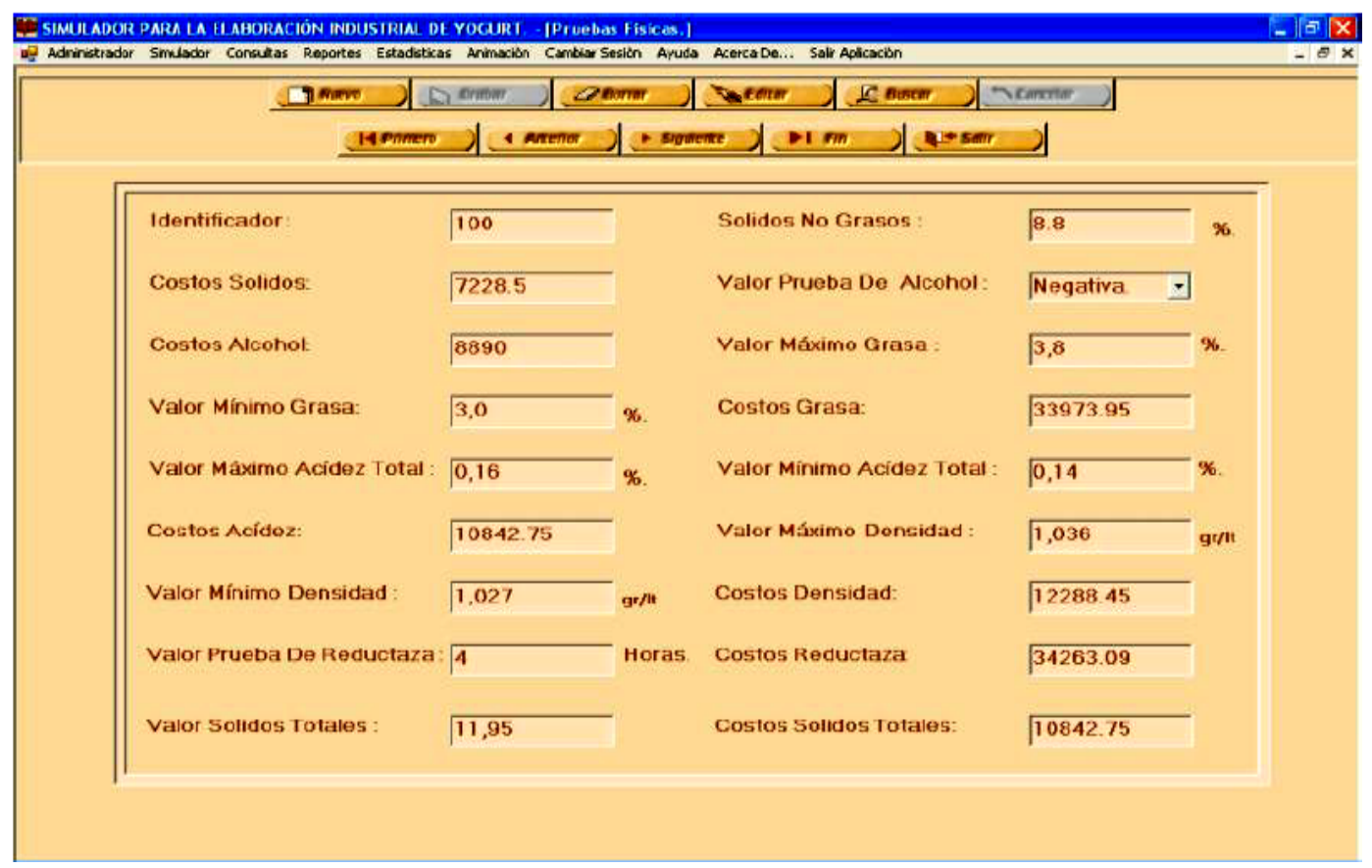

Fig. 4. Administrator/Tests/Physicochemical [17]

The user of the Software in this case the administrator the operator and/or the collector can select the required data previously entered in the administrator menu and for the elaboration of a type of yogurt according to the need. Click on the Simulator menu and this displays a list of the information needed to prepare the final product. The simulator consists of a series of forms where the values of the system variables are recorded, then some are presented. In Fig. 5 you can see the simulator form during the milk reception process.

The query menu format for each of the forms. The date you wish to consult is selected by means of the combo, then click on the consult button located on the right side of the combo and automatically load the information corresponding to that query. The consultations can be carried out by day, week, fortnight and by month. In Fig. 6, the menu can be seen with an example of a form of consultations. 
The report format menu consists of showing the user the most important data of the information handled in the project in a clearer and more orderly manner, in the same way it allows the user to print said reports. The user selects the start date and the final date, and then click on the generate button showing the requested information. In Fig. 7, an example of a report related to the duration of the process and the collection stage is shown.

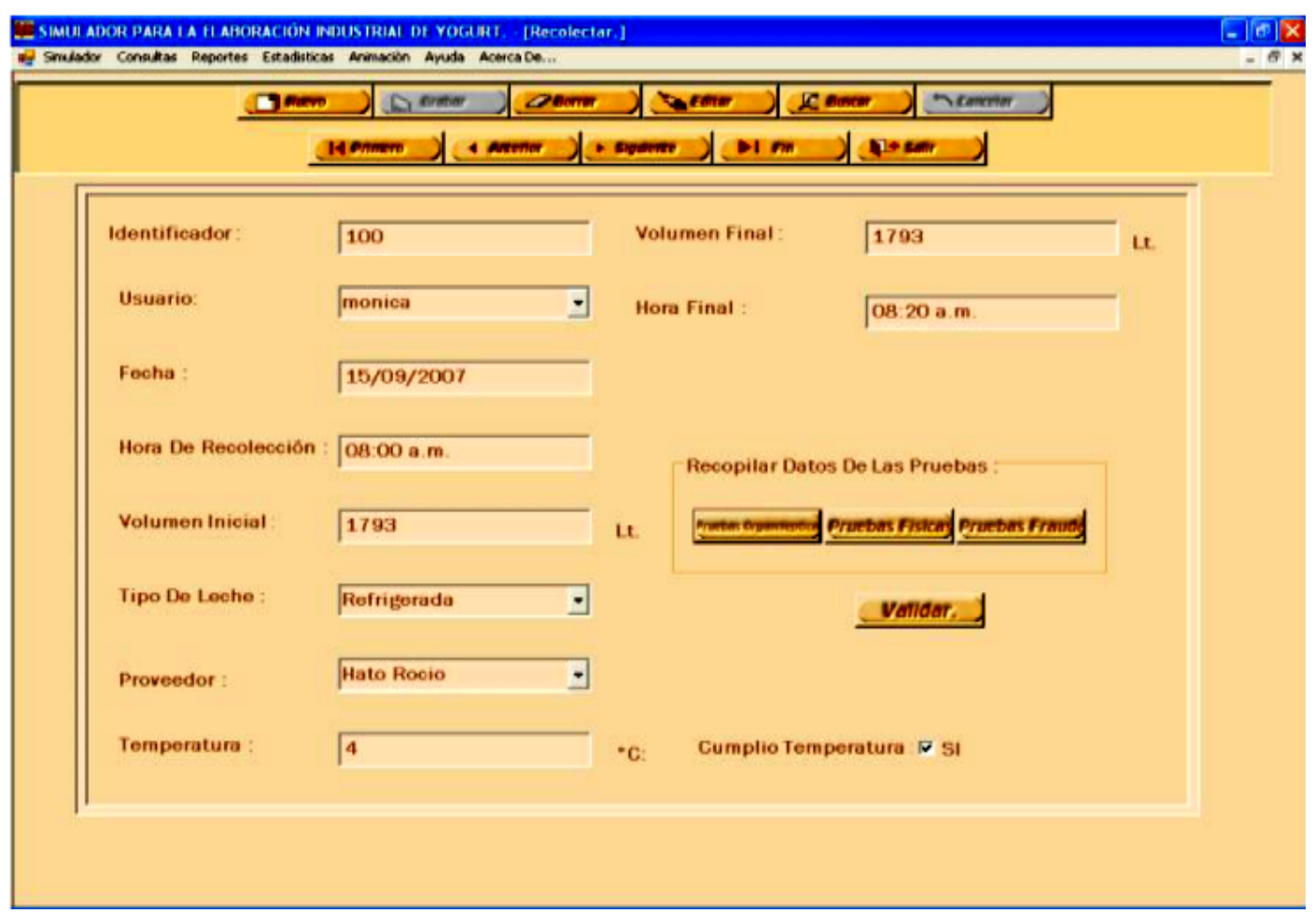

Fig. 5. Simulator/Reception of Milk [17]

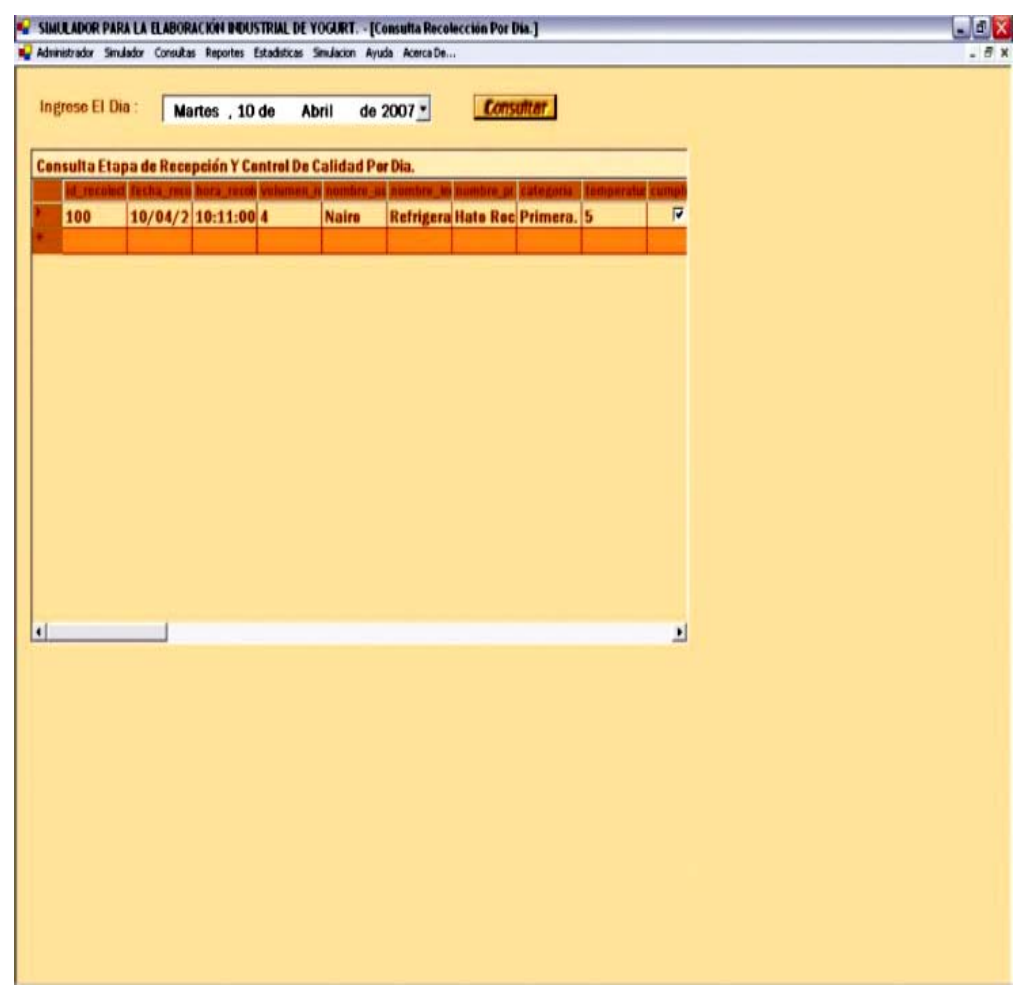

Fig. 6. Check collection per day [17]

The statistics format menus show the user the most important, elementary and necessary states for the manipulation of certain information handled in the project in a clearer and more orderly manner, in the same way it allows the user to print said reports. Fig. 8 shows an example of production volume statistics. 


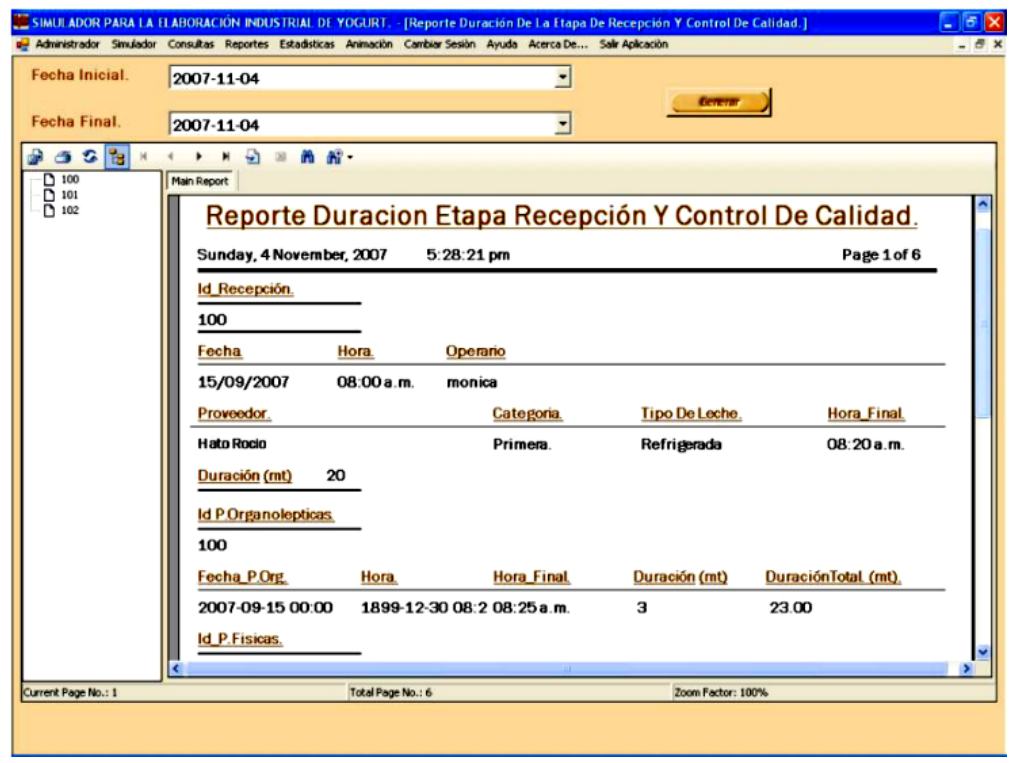

Fig. 7. Reports/Duration of the Process/Stage Collection [17]

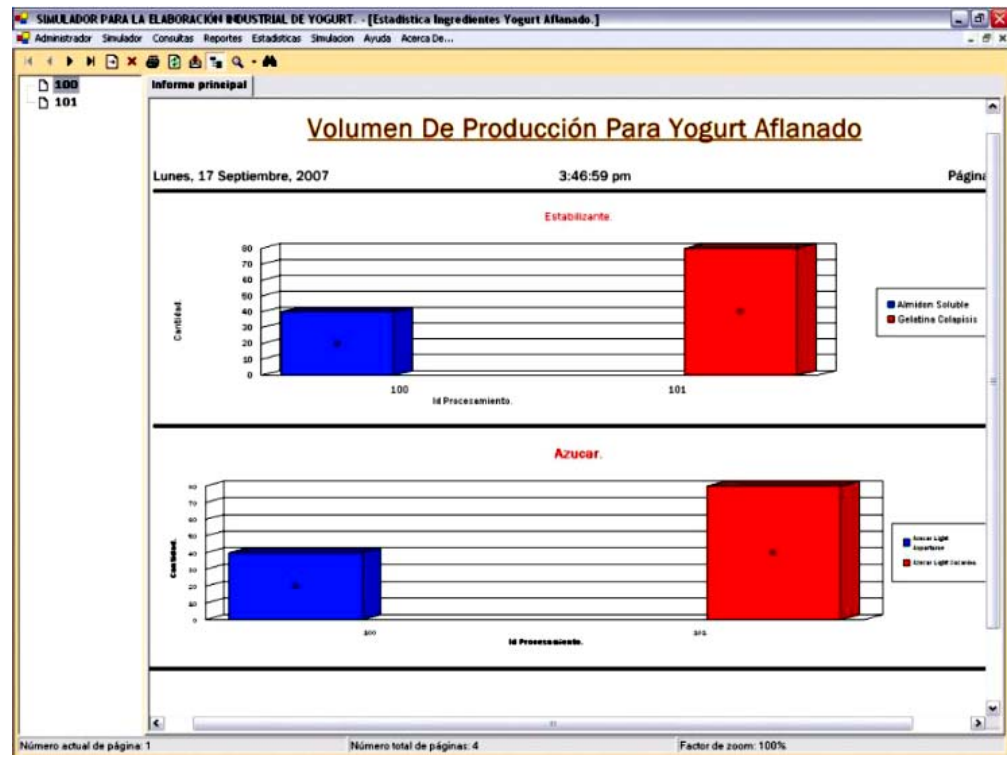

Fig. 8. Statistics/Ingredients flavored yogurt [17]

The animation menu shows dynamically, graphically and animated the process of making yogurt from the collection of milk to the packaging of the final product with its different types of presentation. The user decides at what moment he/she will observe the animation of said process by clicking on the animation option in the main menu. In Fig. 9, the simulation of the third stage related to pasteurization-homogenization is presented.

The session change menu allows the user to start the application again and exit it. You can choose again the type of user you want to enter. The help menu consists of the online help presented by the program so that the user of the Software can find the solution to any doubts he may have about the operation of each of the options that appear in the menus and their management. The user decides at what moment he will use the aids by clicking on the Help option in the main menu 


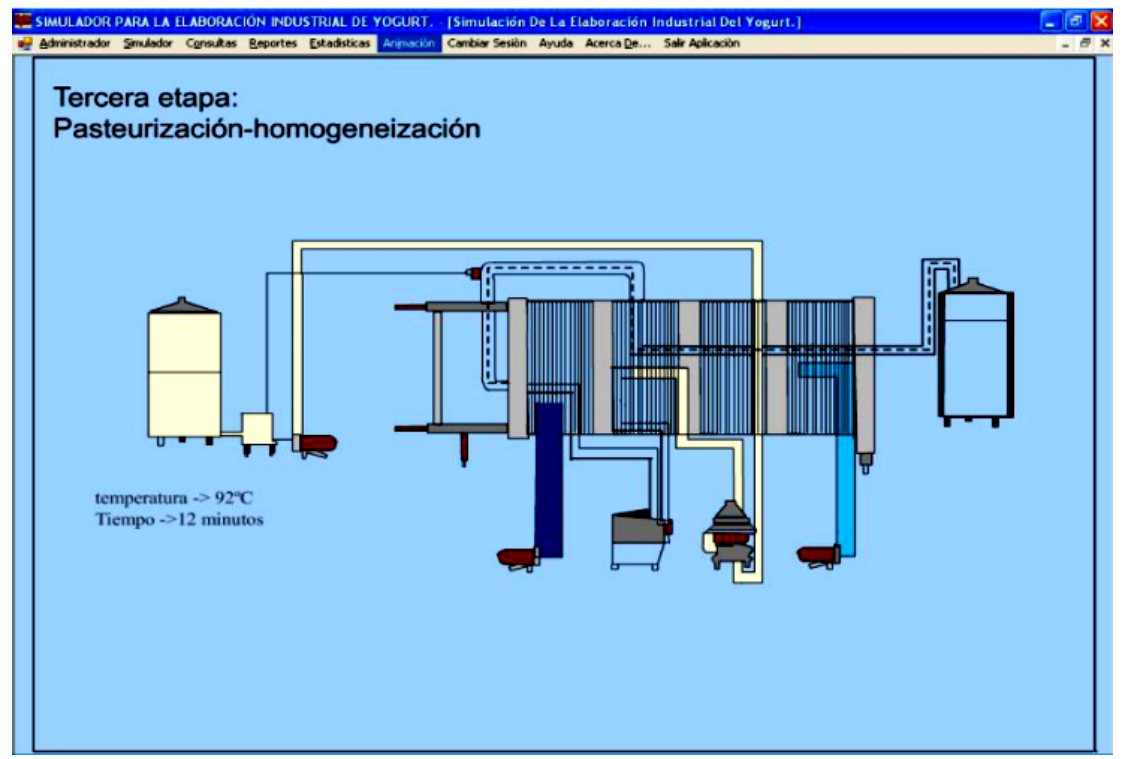

Fig. 9. Animation pasteurization [17]

\section{IV.CONCLUSION}

A simulator based on an automaton was developed and implemented, contributing to the strengthening of industrial food processes, so that they can be controlled by computer in a more efficient and uninterrupted way, and so that the personnel in charge of production can follow up and determine possible faults before they happen, in order to obtain high quality products, saving time and avoiding economic losses.

The development of mathematical models or finite automata is very important in the control of productive processes since it allows simulating them before implementing them, observing the effects produced by the variations of their parameters, which allows to improve the quality of the finished product

\section{REFERENCES}

[1] T. Renji, Finite Automata and Aplication to Criptography, Berlin, Germany: Springer-Verlag, 2009.

[2] S. Gómez et al., Introducción a la computación, México D.F, México: Cengage Learning, 2008.

[3] K. Meer et al., "Generalized finite automata over real and complex numbers," Theoretical Computer Science, vol. 591, pp. 85-98, 2015

[4] M. Rabin “Finite automata and their decision problems,” IBM J. Res. Dev., vol. 3, no. 2, pp. 114-125, 1959

[5] A. Chandra et al., “Alternation,” J. ACM, vol. 28, no. 1, pp. 114-133, 1981.

[6] M. Holzer et al., "Descriptional and computational complexity of finite automata—A survey," Information and Computation, vol. 209, no. 3, pp. 456-470, 2011.

[7] M. Nielsen et al., Quantum Computation and Quantum Information, Cambridge, UK: Cambridge University Press, 2000.

[8] S. Haykin, Neural Networks: A Comprehensive Foundation, $2^{\text {nd }}$ ed. New York, USA: Prentice Hall, 1999.

[9] O. Bournez et al., "A Survey on Continuous Time Computations", in: New Computational Paradigms, New York, USA: Springer, 2008.

[10] G. Paun, Membrane Computing: An Introduction, Berlín, Germany: Springer, 2002.

[11] K. Weihrauch, Computable Analysis: An Introduction, Berlin, Germany: Springer, 2000

[12] L. Blum et al., "On a theory of computation and complexity over the real numbers: NP-completeness, recursive functions and universal machines,” Bull. Amer. Math. Soc, vol. 21, no. 1, pp. 1-46, 1989.

[13] P. Bürgisser et al., "Algebraic Complexity Theory. Grundlehren der mathematischen wissenschaften,” vol. 315, Berlin, Germany: Springer Verlag, 1997

[14] Instituto Colombiano de Normas Técnicas y Certificación. Manual de métodos fisicoquímicos para el control de calidad de leche y sus derivados, ICONTEC, Bogotá, Colombia 1993.

[15] P. Keating, Introducción a la lactología, México D.F., México: Limusa, 1999.

[16] M. Hernández, "Elaboración del yogur a pequeña escala en el hogar,” Revista Cubana de Alimentación y Nutrición, vol. 12, no. 1, pp. 55-57, 1998.

[17] M. Mancipe et al., "Desarrollo de un simulador para el proceso industrial del Yogurt, Trabajo de Grado, Universidad de Boyacá, Tunja, Colombia 2007.

[18] N. Cavieles et al., "Modelo de autómata finito orientado a mejorar la productividad en el procesamiento de yogur," Educación en Ingeniería, vol. 7, no. 13, pp. 63-73, 2012. 